\title{
Evaluation of Methanol-Water and Acetonitrile-Water Binary Mixtures as Eluents for Temperature-dependent Inclusion Chromatography
}

\author{
Paweł K. ZarzyCKI, ${ }^{* * * \dagger}{ }^{*}$ Elżbieta WŁOdARCZYK, ${ }^{*}$ Da-Wei Lou,** and Kiyokatsu JINNO** \\ *Laboratory of Toxicology, Department of Environmental Biology, Technical University of Koszalin, \\ 75-453 Koszalin, Poland \\ **School of Materials Science, Toyohashi University of Technology, Toyohashi 441-8580, Japan
}

\begin{abstract}
In the present study the solubility of $\beta$-cyclodextrin and 2-hydroxypropyl- $\beta$-cyclodextrin at sub-zero and elevated temperatures $\left(-10\right.$ and $\left.+30^{\circ} \mathrm{C}\right)$ for a given composition of methanol/water and acetonitrile/water binary mixtures $\left(X_{\mathrm{s}}=\right.$ $0.16)$ was studied. Moreover, the freezing temperature profiles of acetonitrile-based chromatographic mobile phases were measured, and the obtained results were compared with data available in the literature. Furthermore, the effect of the macrocycles concentration on the liquid-phase freezing points was determined. The low solubility of native $\beta$ cyclodextrin in a methanol/water mixture at sub-zero temperature as well as the non-linear behavior of acetonitrile/water mixtures that were observed concerning the freezing point profile are discussed from a practical point of view.
\end{abstract}

(Received October 4, 2005; Accepted January 13, 2006)

\section{Introduction}

It is well known that the retention of a number of low-molecular mass compounds, including polycyclic aromatic hydrocarbons or steroids, is strongly influenced by the temperature when the eluent is modified with macrocyclic additives particularly. Moreover, the solubility of solid additives, like buffer components or chiral additives, is usually strongly affected by the temperature. ${ }^{2}$ In some cases the additives solubility significantly changes within a relatively small temperature region. ${ }^{3}$ For that reason the effective use of relatively lowsoluble host-guest modifiers, such $\beta$-cyclodextrin, at a high concentration and low temperature, is strongly limited, and may even cause column and detector failure, or damage. On the other hand, the separation of complex mixtures using the abovementioned mobile phases may be very effective, particularly at sub-zero temperatures. ${ }^{4}$ Therefore, the solubility of chiral additives seems to be one of the important factors for designing proper and "hardware safe" separation systems.

Methanol and acetonitrile are commonly used as organic components of the mobile phases for a number of prepurification and separation techniques, including liquid or solidphase extraction and capillary electrophoresis as well as planar and column chromatography. ${ }^{5}$ It is noteworthy that both molecules weakly interact with the internal cavities of common

\footnotetext{
† To whom correspondence should be addressed.

E-mail: pkzarz@wp.pl; pawel_k_z@hotmail.com

Currently the JSPS Fellow at School of Materials Science, Toyohashi University of Technology, Toyohashi 441-8580, Japan. On leave from Laboratory of Toxicology, Department of Environmental Biology, Technical University of Koszalin, Śniadeckich 2, 75-453 Koszalin and Department of Pharmaceutical Chemistry, Medical University of Gdańsk, Hallera 107, 80-416 Gdańsk, Poland.
}

mobile-phase macrocyclic additives, such cyclodextrins. Therefore, they were often applied as co-solvents for bindingconstant measurements. ${ }^{6,7}$ Furthermore, they have been frequently used as the main mobile-phase organic components for the separation of stereoisomers using chromatographic systems based on the host-guest phenomenon. ${ }^{1,8}$

The basic physical constants of organic liquids, including the freezing points of pure solvents and their mixtures with water, are easily available through a number of reference handbooks. ${ }^{9,10}$ In contrast to such constants that are available for $n$-alcohols, the freezing-point data of acetonitrile are notconsistent. Depending on the author, this parameter changes even by $5^{\circ} \mathrm{C}$ within the range from -46 to $-41^{\circ} \mathrm{C} .^{9-12}$ Recently, a few authors investigated a liquid-liquid equilibrium of binary acetonitrile-water mixtures at sub-ambient temperatures. ${ }^{13-15}$ However, to our knowledge there is just one publication dealing with the freezing-point profiles of the acetonitrile-water mixtures across the whole range of the binary phase concentration that was published in 1996 by Che and coauthors. ${ }^{16}$ There is also a lack of solubility data for the native and modified cyclodextrins, particularly for given organic-water mixtures at sub-ambient temperatures below $0^{\circ} \mathrm{C}$.

The results of our previous studies concerning the chromatographic behavior of different classes of solutes in the presence of a macrocyclic additive in the mobile phase has indicated that the retention of inclusion complexes can be varied between two lines formed by the van't Hoff plot of the free macrocycle and the van't Hoff plot of the uncomplexed analyte. ${ }^{1,4,7}$ Simply, at low temperature the inclusion modifier action is more efficient due to the high values of the binding constant of the complexes created and the large differences in the retention of free macrocycle and uncomplexed solutes. Therefore, from a practical point of view, the solubility and freezing-point data are the key factors for designing separation systems based on temperature-dependent inclusion chromatography. Hence, the objectives of this work were to 
measure the solubility of $\beta$-cyclodextrin and 2-hydroxypropyl$\beta$-cyclodextrin at different temperatures and for given mobilephase compositions as well as freezing-point profiles for selected binary organic solvent/water mixtures, ranging from 0 to $100 \%(\mathrm{v} / \mathrm{v})$. Moreover, the effect of the macrocycles concentration on the liquid-phase freezing points was also studied.

\section{Experimental}

\section{Chemicals}

Acetonitrile (HiPerSolv for HPLC; 99.9\%) was a product of BDH Laboratory Supplies (Poole, England). Methanol (HPLC grade $99.8 \%$ ) was obtained from Merck (Darmstadt, Germany). The organic solvents were used without further purification. Deionized water was double distilled before solvent preparation. All of the binary mixtures were prepared as a volume/volume percent of the organic solvent in water. The macrocycles $(\beta$ cyclodextrin and 2-hydroxypropyl- $\beta$-cyclodextrin) were purchased from Fluka Chemie AG (Buchs, Switzerland) and used as received.

\section{Freezing temperature measurement}

A freezing-point study of the liquids was based on the heat-offusion phenomenon. In our experiment, a small plastic tube (V $=10 \mathrm{~mL}, \phi=1 \mathrm{~cm} ; \mathrm{H}=10 \mathrm{~cm}$ ) was equipped with a temperature sensor (glass NTC thermistor), a few glass beads ( $\phi$ $\approx 1 \mathrm{~mm}$ ) and a mechanical stirrer (stainless-steel rod), and was filled with $2 \mathrm{~mL}$ of the investigated liquid. The tube with the sample was placed in a thermostatic bath that included an ethylene glycol/water mixture (for temperatures up to $-20^{\circ} \mathrm{C}$ ) or a glass cylinder with methanol, which was deposited in a dryice container (for temperatures below $-20^{\circ} \mathrm{C}$ ). The sample was immediately and continuously stirred and the temperature changes were recorded using the Appa 305 Digital Multimeter (from Appa Technology Corp., Taipai, Taiwan, R. O. C.) and saved by a computer data-acquisition system through the APPA WinDMM v.1.52E software. During the cooling process the sample was supercooled several degrees below its freezing point, and finally mechanically induced to freeze because of continuous stirring. After that, due to the heat of fusion the temperature of the sample increased to the freezing-point level. All of the measurements were performed under atmosphericpressure conditions; typical temperature profiles recorded by the described system are shown in Fig. 1.

\section{Solubility determination}

Accurately weighed amounts of $\beta$-cyclodextrin and 2hydroxypropyl- $\beta$-cyclodextrin were suspended in $0.5 \mathrm{~mL}$ of methanol:water $(30 \% \mathrm{v} / \mathrm{v})$ and acetonitrile:water $(35.6 \% \mathrm{v} / \mathrm{v})$ binary solvents $\left(X_{\mathrm{s}}=0.16\right)$. Then $5 \mathrm{~mL}$ plastic tubes containing macrocycles-liquid mixtures were sonicated for $10 \mathrm{~min}$ at room temperature, and then transferred to a constant-temperature bath set at $+30^{\circ} \mathrm{C}$ or $-10^{\circ} \mathrm{C}$, and then stirred for 5 days. The temperature of the samples was controlled with an accuracy of $\pm 0.01^{\circ} \mathrm{C}$ using a Polystat digital circulating thermostat (Model 12101-15; Cole Parmer, Chicago, IL, USA). After equilibrium was reached the solutions were separated from solid particles by spinning them at appropriate sub-ambient or elevated temperatures. The concentration of macromolecules in the obtained clear solution was quantified immediately using a photometric detection method based on supramolecular complex formation with phenolphthalein. ${ }^{17-19}$
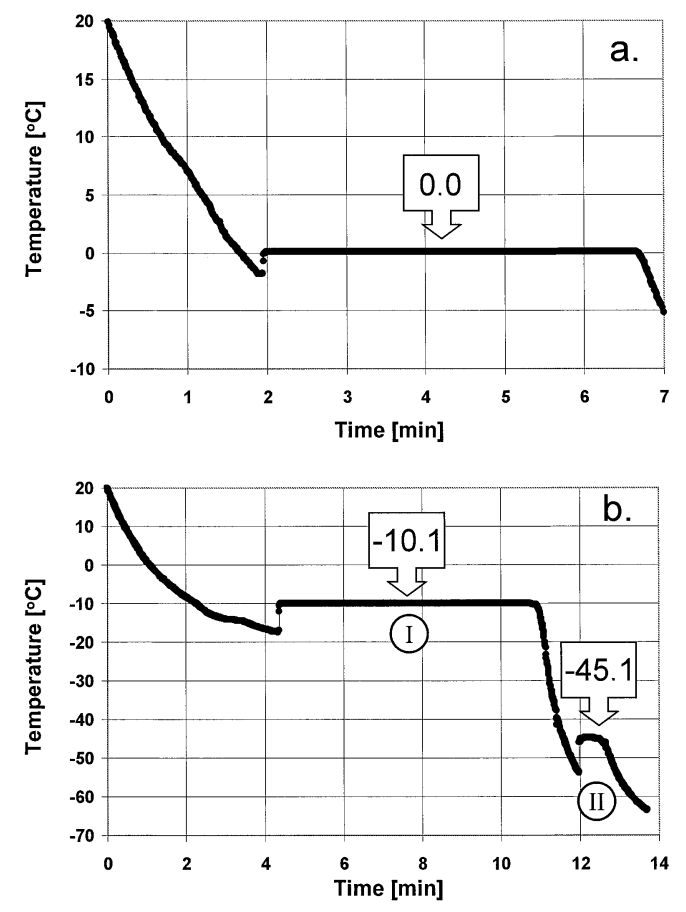

Fig. 1 Freezing temperature profiles of pure water (a) and an acetonitrile-water mixture at a concentration $35.6 \% \mathrm{v} / \mathrm{v}(\mathrm{b})$. The Xaxis measurement error does not exceed $\pm 0.3^{\circ} \mathrm{C}$.

\section{Results and Discussion}

The liquid structure of acetonitrile and methanol with water binary mixtures is still of research interest, and remains unresolved. As a result of strong hydrogen bonding and selfassociated forms of organic components, the solvation structures of acetonitrile/water and methanol/water mixtures are substantially different. ${ }^{20}$ The experimental data revealed that an acetonitrile-water mixture should be considered at least as a ternary system in which two distinct forms of acetonitrile in solution exists. ${ }^{21}$ This phenomenon strongly affects the number of physical and chemical properties of acetonitrile/water mixtures. The data reported by Gu and co-workers show that if the acetonitrile/water mixture is stored for several hours at a sub-ambient temperature an unexpected phase separation can be observed in such a simple system. ${ }^{13}$ It has been found that phase separation takes place at temperatures below $-1.32^{\circ} \mathrm{C}$, and can be observed within a wide range of acetonitrile concentrations from $31 \%$ to $89 \%(\mathrm{v} / \mathrm{v})$, which correspond to mole fractions $X_{\mathrm{S}, \mathrm{ACN}}$ from 0.134 to $0.738 .{ }^{14}$ Under the described conditions the acetonitrile is distributed between two phases. The top phase contains $88 \%(\mathrm{v} / \mathrm{v})$ of acetonitrile and the bottom phase consists of $65 \%(\mathrm{v} / \mathrm{v})$ of water.

A typical freezing curve of an acetonitrile/water mixture $\left(X_{\mathrm{S}, \mathrm{ACN}}=0.160 \approx 35.6 \% \mathrm{v} / \mathrm{v}\right)$ measured in our laboratory is presented in Fig. 1. The data show that under such experimental conditions two freezing-point temperatures may be observed. Particularly, it has been found that the freezing point of the water-rich phase is $-10.1{ }^{\circ} \mathrm{C}$, and the freezing temperature of an acetonitrile-rich liquid corresponds to $-45.1^{\circ} \mathrm{C}$. Moreover, the freezing curve profile reveals that both liquid phases may be significantly supercooled, even at $10^{\circ} \mathrm{C}$ below the main freezing-point temperature. As is expected under the same conditions, the methanol-water mixture 


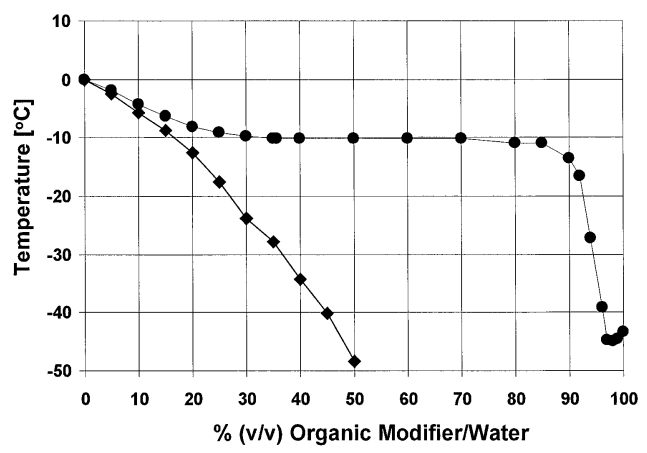

Fig. 2 Freezing temperature trajectories for binary mobile phases composed of methanol-water (diamonds) and acetonitrile-water (dots). The $\mathrm{X}$-axis measurement error does not exceed $\pm 0.3^{\circ} \mathrm{C}$.

$\left(X_{\mathrm{S}, \mathrm{MetOH}}=0.160 \approx 30.0 \% \mathrm{v} / \mathrm{v}\right)$ profile shows just one freezing point at a temperature of $-23.4^{\circ} \mathrm{C}$ (an appropriate freezing curve in Fig. 1 is not visualized).

The entire freezing-point profiles for methanol-water mixtures ranging from 0 to $50 \%(\mathrm{v} / \mathrm{v})$ and acetonitrile/water mixtures across the whole range of concentrations are displayed in Fig. 2. The freezing curve for the methanol/water mixtures that was measured in our laboratory is in good agreement with the data published e.g. by Merck. ${ }^{9}$ As can be seen, the acetonitrile/water freezing profile is very complex. Starting from $0 \%$ of acetonitrile, the freezing temperature systematically drops from 0 to $-10^{\circ} \mathrm{C}$ at $25 \%(\mathrm{v} / \mathrm{v})$ of $\mathrm{ACN}$ in water. Within the concentration range from 30 to $85 \%$ the freezing point of the mixture is constant and corresponds to the freezing temperature of the water-rich phase, which was quantified as $-10.1^{\circ} \mathrm{C}$. Accordingly to the data published by $\mathrm{Gu}$ and co-workers, two separate acetonitrile and water-rich phases may co-exist within this concentration area. ${ }^{13}$ Therefore, the water-rich phase is "buffering" the freezing-point temperature of the mixture, and a freezing point-plateau is observed for a wide range of acetonitrile concentrations. Starting from $90 \%$ of the organic component, the freezing temperature rapidly decreases. The minimum temperature of $-44.9^{\circ} \mathrm{C}$ was observed for a mixture consisting of $98 \%$ of acetonitrile in water. The freezing temperature of pure acetonitrile that was used in our experiment was determined as $-43.4^{\circ} \mathrm{C}$. Interestingly, the shape of the right side of the freezing-point trajectory starting from $97 \%$ may explain the differences in the freezing point temperatures of pure acetonitrile that are present in the literature. ${ }^{9-12}$ Our results may suggest that this parameter can change significantly due to small residues of water. Similar results were obtained by Che and co-authors, who measured the freezing curve of acetonitrile/water mixtures under a nitrogen atmosphere. ${ }^{16}$ Despite of a good agreement with the freezing temperatures of pure water $(273.14 \mathrm{~K})$ and pure acetonitrile (229.74 and 229.21 $\mathrm{K}$; Che data) the minimum freezing temperatures were slightly different $(228.21$ and $227.44 \mathrm{~K})$, and were observed for different acetonitrile concentrations: $X_{\mathrm{s}}=0.94$ and $X_{\mathrm{s}}=0.96$, respectively. Moreover, a different shape of the freezing curve in this region was also observed.

Temperature-dependent inclusion chromatography requires the presence of macrocyclic additives in mobile phases, especially those that are not retarded by the stationary-phase components. ${ }^{4}$ The number of presently existing protocols for the efficient separation of low molecular mass stereoisomers involves the application of native $\beta$-cyclodextrin $(\beta-\mathrm{CD})$, or its very well water-soluble derivatives, for example 2-
Table 1 Solubility of $\beta$-cyclodextrin and 2-hydroxypropyl- $\beta$ cyclodextrin in methanol/water and acetonitrile/water binary mobile phases $\left(X_{\mathrm{s}}=0.16\right)$ at different temperatures

\begin{tabular}{ccccccc}
\hline \multirow{2}{*}{$\begin{array}{c}\text { Temperature/ } \\
{ }^{\circ} \mathrm{C}\end{array}$} & \multicolumn{2}{c}{$\beta$-Cyclodextrin/mM } & & \multicolumn{2}{c}{$\begin{array}{c}\text { 2-Hydroxypropyl- } \beta- \\
\text { CD/mM }\end{array}$} \\
\cline { 2 - 3 } \cline { 5 - 6 } & $\begin{array}{c}\text { Methanol/ } \\
\text { water }\end{array}$ & $\begin{array}{c}\text { Acetonitrile/ } \\
\text { water }\end{array}$ & & $\begin{array}{c}\text { Methanol/ } \\
\text { water }\end{array}$ & $\begin{array}{c}\text { Acetonitrile/ } \\
\text { water }\end{array}$ \\
\hline+30 & $8.9 \pm 0.3$ & $25.4 \pm 0.5$ & & $>717$ & $>717$ \\
-10 & $1.63 \pm 0.04$ & $7.9 \pm 0.1$ & & $>437$ & $>437$ \\
\hline
\end{tabular}

Number of samples, 5 .

hydroxypropyl- $\beta$-cyclodextrin (HPBCD). In our experiment the solubility of $\beta$-CD in water at $30^{\circ} \mathrm{C}$ was determined to be 2.25 $\mathrm{g} / 100 \mathrm{~mL}(19.8 \mathrm{mM})$, which is in close agreement with the literature value of $2.30 \mathrm{~g} / 100 \mathrm{~mL} .22$ Although HPBCD is completely soluble in water up to a concentration of $70 \%(\mathrm{w} / \mathrm{w})$, a strong increase in the viscosity can be observed for concentrations beyond $50 \%(\mathrm{w} / \mathrm{w}) .^{23}$

The solubility of cyclodextrins in binary organic/water mixtures is very complex, and usually non-linear. ${ }^{22}$ For most of the isocratic separations that involve cyclodextrin additives, the concentration of water should be as high as possible to allow good solubility of such macrocycles in the mobile phases. Therefore, a concentration of organic liquids that is close to the mole fraction of $X_{\mathrm{s}}=0.16$ is often used. ${ }^{4,24}$ The solubility data for that mole fraction point and different temperatures are presented in Table 1. Under elevated temperature conditions, $\beta$ cyclodextrin is almost three-times more soluble in acetonitrile/water than a methanol/water mixture, which was previously observed. ${ }^{22}$ At sub-zero temperature the change in solubility between both phases is more evident (almost 5 times). If we compare each mixture at different temperatures, the solubility of $\beta$-CD in methanol/water and acetonitrile/water is changes 5 and 3 times, respectively. It is noteworthy that the HPBCD derivative is at least two factors more soluble than native $\beta$-CD under all of the conditions investigated. However, its application in liquid chromatography at a very high concentration level (e.g. more than $100 \mathrm{mM}$ ) is strongly limited due to the high viscosity of the solution. The data presented in Table 2 show that the presence of both macrocycles did not appear to have a significant effect on the freezing-point temperatures of the investigated mobile phases.

\section{Conclusions}

The application of binary acetonitrile/water mixtures for temperature optimization in column chromatography is limited to $-10^{\circ} \mathrm{C}$ within a wide range of acetonitrile concentrations from 25 to $85 \%(\mathrm{v} / \mathrm{v})$. From that point of view, the methanol/water phases allow the use of sub-zero temperatures beyond $-10^{\circ} \mathrm{C}$ (for methanol concentrations ranging from $20 \%$ to $100 \%$ ).

Under sub-zero temperature $\beta$-cyclodextrin is almost 5 -times more soluble in acetonitrile/water than in a methanol/water mixture (1.6 and $7.9 \mathrm{mM}$, respectively). Therefore, the effective application of $\beta$-cyclodextrin as a modifier of mobile phases based on methanol/water mixtures at sub-ambient temperature may be strongly limited. It is noteworthy that the HPBCD derivative is at least two factors more soluble than native $\beta$-CD under all of the conditions investigated. 
Table 2 Freezing temperatures $\left({ }^{\circ} \mathrm{C}\right)$ of acetonitrile/water $(35.6 \%, \mathrm{v} / \mathrm{v})$ and methanol/water $(30.0 \%$, v/v) binary mobile phases unmodified and modified with $\beta$-cyclodextrin and 2-hydroxypropyl- $\beta$-cyclodextrin

\begin{tabular}{|c|c|c|c|c|c|c|c|}
\hline & \multicolumn{7}{|c|}{$\mathrm{CD}$ concentration $/ \mathrm{mM}$} \\
\hline & 0 & 0.1 & 1 & 5 & 10 & 50 & 100 \\
\hline \multicolumn{8}{|l|}{ Acetonitrile/Water } \\
\hline$\beta$-Cyclodextrin & $\begin{array}{l}-10.08 \\
( \pm 0.01)\end{array}$ & $\begin{array}{l}-10.09 \\
( \pm 0.01)\end{array}$ & $\begin{array}{l}-10.09 \\
( \pm 0.01)\end{array}$ & $\begin{array}{l}-10.10 \\
( \pm 0.01)\end{array}$ & NA & NA & NA \\
\hline 2-Hydroxypropyl- $\beta$-CD & $\begin{array}{l}-10.08 \\
( \pm 0.01)\end{array}$ & $\begin{array}{l}-10.07 \\
( \pm 0.05)\end{array}$ & $\begin{array}{l}-10.06 \\
( \pm 0.04)\end{array}$ & $\begin{array}{l}-10.08 \\
( \pm 0.02)\end{array}$ & $\begin{array}{l}-10.12 \\
( \pm 0.03)\end{array}$ & $\begin{array}{l}-10.295 \\
( \pm 0.007)\end{array}$ & $\begin{array}{l}-10.532 \\
( \pm 0.005)\end{array}$ \\
\hline $\begin{array}{l}\text { Methanol/Water } \\
\beta \text {-Cyclodextrin }\end{array}$ & $\begin{array}{l}-23.4 \\
( \pm 0.5)\end{array}$ & $\begin{array}{l}-24.3 \\
( \pm 0.4)\end{array}$ & $\begin{array}{l}-23.6 \\
( \pm 0.8)\end{array}$ & NA & NA & NA & NA \\
\hline 2-Hydroxypropyl- $\beta$-CD & $\begin{array}{l}-23.4 \\
( \pm 0.5)\end{array}$ & $\begin{array}{l}-24.3 \\
( \pm 0.2)\end{array}$ & $\begin{array}{l}-23.8 \\
( \pm 0.7)\end{array}$ & $\begin{array}{l}-23.6 \\
( \pm 0.7)\end{array}$ & $\begin{array}{l}-23.3 \\
( \pm 0.2)\end{array}$ & $\begin{array}{l}-24.0 \\
( \pm 0.6)\end{array}$ & $\begin{array}{l}-25.0 \\
( \pm 0.4)\end{array}$ \\
\hline
\end{tabular}

NA: Non available. The numbers in parentheses correspond to the standard deviation values; number of samples, 5.

\section{References}

1. P. K. Zarzycki and H. Lamparczyk, Chromatographia, 1998, 48,377 .

2. A. P. Schellinger and P. W. Carr, $L C G C, \mathbf{2 0 0 4}, 22,544$.

3. A. K. Chatjigakis, C. Donzé, A. W. Coleman, and P. Cardot, Anal. Chem., 1992, 64, 1632.

4. P. K. Zarzycki and R. Smith, J. Chromatogr., A, 2001, 912 , 45.

5. P. C. Sadek, "The HPLC Solvent Guide", 2nd ed., 2002, Wiley.

6. K. A. Connors, "Binding Constants. The Measurement of Molecular Complex Stability", 1987, John Wiley \& Sons, Inc., USA.

7. P. K. Zarzycki and H. Lamparczyk, J. Pharm. Biomed. Anal., 1998, 18, 165.

8. D. Sybilska and J. Żukowski, in "Chiral Separations by HPLC", 1989, Ellis Horwood, Chichester, UK, 147.

9. The Merck Index, 10th ed., 1983, Merck \& Co., Inc., Rahway, NJ, USA.

10. R. C. Weast (ed.), "CRC Handbook of Chemistry and Physics", 65th ed., 1985, CRC Press, Inc., Boca Raton, Florida.

11. M. Grayson (ed.), "Kirk-Othmer Concise Encyclopedia of
Chemical Technology", 1985, Maruzen Co., Tokyo.

12. K. Verschueren, "Handbook of Environmental Data on Organic Chemicals", 2nd ed., 1983, Van Nostrand Reinhold Co., New York.

13. T. Gu, Y. Gu, Y. Zheng, P. E. Wielh, and J. J. Kopchick, Separ. Technol., 1994, 4, 258.

14. D. N. Pence and T. Gu, Separ. Technol., 1996, 6, 261.

15. Y. Gu and P.-H. Shih, Enzyme Microb. Technol., 2004, 35, 592.

16. G. Q. Che, Z. Q. Huang, and F. C. Yun, Acta Chim. Sin., 1996, 54,859 .

17. Y. Matsui and K. Mochida, Bull. Chem. Soc. Jpn., 1979 52, 2808.

18. K. Taguchi, J. Am. Chem. Soc., 1986, 108, 2705.

19. T. Takeuchi and T. Miwa, Chromatographia, 1994, 38, 453.

20. A. Alvarez-Zepeda, B. N. Barman, and D. E. Martire, Anal. Chem., 1992, 64, 1978.

21. K. L. Rowlen and J. M. Harris, Anal. Chem., 1991, 63, 964.

22. A. K. Chatjigakis, C. Donzé, and A. W. Coleman, Anal. Chem., 1992, 64, 1632.

23. O. Häusler and Ch. Müller-Goymann, Starch, 1993, 45, 183.

24. P. K. Zarzycki, K. M. Kulhanek, and R. Smith, J. Chromatogr., A, 2002, 955, 71. 